\title{
Association between Dipeptidyl Peptidase-4 Inhibitor Prescription and Erythropoiesis- Stimulating Agent Hyporesponsiveness in Hemodialysis Patients with Diabetes Mellitus
}

\author{
Takeshi Hasegawa ${ }^{a, b}, c, d, e$ Junhui Zhao ${ }^{f}$ Brian Bieber $^{f}$ Jarcy Zee ${ }^{f}$ \\ Ronald L. Pisoni ${ }^{f}$ Bruce M. Robinson ${ }^{f}$ Norio Hanafusa ${ }^{e, g}$ Masaomi Nangaku ${ }^{e, h}$ \\ aShowa University Research Administration Center (SURAC), Showa University, Tokyo, Japan; 'bivision of \\ Nephrology, Department of Medicine, School of Medicine, Showa University, Tokyo, Japan; 'Department of Hygiene, \\ Public Health, and Preventive Medicine, Graduate School of Medicine, Showa University, Tokyo, Japan; ${ }^{\mathrm{d} C e n t e r}$ for \\ Innovative Research for Communities and Clinical Excellence, Fukushima Medical University, Fukushima, Japan; \\ eAnemia Working Group of the Japan Dialysis Outcomes and Practice Patterns Study (J-DOPPS), Osaka, Japan; \\ fArbor Research Collaborative for Health, Ann Arbor, MI, USA; 9Department of Blood Purification, Tokyo Women's \\ Medical University, Tokyo, Japan; 'Division of Nephrology and Endocrinology, The University of Tokyo Graduate \\ School of Medicine, Tokyo, Japan
}

\section{Keywords \\ Dipeptidyl peptidase-4 inhibitor · Erythropoiesis- stimulating agent · Hemodialysis · Diabetes mellitus}

\begin{abstract}
Introduction: Dipeptidyl peptidase-4 (DPP-4) has been hypothesized to improve responsiveness to erythropoiesisstimulating agent (ESA). We aimed to describe the trend in DPP-4 inhibitor prescription patterns and assess the association between DPP-4 inhibitor prescription and ESA hyporesponsiveness (eHypo) in Japanese hemodialysis (HD) patients with diabetes mellitus (DM). Methods: We analyzed data from the Japan Dialysis Outcomes and Practice Patterns Study phase 4-6 (2009-2017) on patients with DM who underwent HD thrice per week for at least 4 months. The primary exposure of interest was having a DPP-4 inhibitor prescription. The primary analysis outcomes were a binary indicator of eHypo (mean hemoglobin $<10$ and mean ESA dose $>6,000$ units/week over 4 months) and the natural log-transformed ESA resistance index (ERI). We used conditional logis-
\end{abstract}

tic regression to compare within-patient changes in eHypo before and after initial DPP-4 inhibitor prescription. We used linear generalized estimating equation models to compare continuous ERI outcomes while accounting for within-patient repeated measurements with an exchangeable correlation structure. Results: There was a monotonic increase in DPP-4 inhibitor prescription according to study year up to $20 \%$ in 2017 . Moreover, $12.8 \%$ of patients with a DPP-4 inhibitor prescription were ESA hyporesponsive before the initial DPP-4 inhibitor prescription. After DPP-4 inhibitor prescription, the odds of eHypo and mean log-ERI remained unchanged in the whole cohort of our study. The interaction analysis of DPP-4 inhibitor and sideropenia showed that DPP-4 inhibitors attenuated eHypo in the patients without iron deficiency. Conclusion: Our findings indicate a recent increase in DPP-4 inhibitor prescription among Japanese HD patients with DM. DPP-4 inhibitors could improve ERI in patients undergoing HD without iron deficiency.

(c) 2021 The Author(s).

Published by S. Karger AG, Basel karger@karger.com www.karger.com/kbr

Karger $\frac{1}{6}$

GOPEN ACCESS
(C) 2021 The Author(s)

Published by S. Karger AG, Basel

This is an Open Access article licensed under the Creative Commons Attribution-NonCommercial-4.0 International License (CC BY-NC) (http://www.karger.com/Services/OpenAccessLicense), applicable to the online version of the article only. Usage and distribution for commercial purposes requires written permission.
Correspondence to:

Takeshi Hasegawa, tahasegawa@med.showa-u.ac.jp 


\section{Introduction}

Currently, limited treatment options are available glycemic control in hemodialysis (HD) patients with diabetes, as severe kidney dysfunction causes drug and metabolite accumulation [1]. Dipeptidyl peptidase-4 (DPP-4) inhibitors are a new class of oral diabetes drugs that is well tolerated even in patients with severe renal dysfunction. DPP-4 inhibitors improve glycemic control by stimulating glucose-dependent insulin secretion from pancreatic beta cells and suppressing glucagon secretion from alpha cells by inhibiting the degradation of incretins such as type 1 glucagon-like peptide (GLP-1). DPP-4 inhibitors also act directly on other organs besides the pancreas via the GLP-1 receptors; thus, they are expected to have multifaceted clinical effects beyond the improvement in glycemic control [2]. Therefore, they are widely used not only in patients with pre-HD CKD but also in HD patients.

Previous studies have reported that the patients undergoing HD with erythropoiesis-stimulating agent (ESA) hyporesponsiveness (eHypo) had increased risk of death [37]. Consequently, eHypo has received increasing attention in renal anemia practice. DPP-4 decreases erythropoietin activity by cleavage and negatively regulates colony-stimulating factor activity and stress hematopoiesis $[8,9]$. This theoretically indicates that DPP-4 inhibitors could improve eHypo. DPP-4 inhibitors also have anti-oxidative stress, anti-inflammatory, and anti-hematopoietic disorder effects [10-15]. Thus far, there have been very few clinical studies on DPP-4 inhibitors and eHypo [16, 17]. The aforementioned findings suggest an association between improved eHypo and DPP-4 inhibitor use. However, there remains no strong evidence of an association between DPP-4 inhibitors and eHypo as there have been no related long-term observational studies in a real-world setting. We, therefore, aimed to describe the trend in DPP-4 inhibitor prescription patterns and assess the association between DPP-4 inhibitor prescription and ESA responsiveness in Japanese HD patients in the Japan Dialysis Outcomes and Practice Patterns Study (J-DOPPS) cohort.

\section{Materials and Methods}

\section{Study Design, Population, and Data Source}

J-DOPPS is a prospective cohort study on HD patients aged $\geq 18$ years who are treated at Japanese HD facilities. The patients are randomly selected to serve as a national sample that is representative of Japanese HD practice. In the present study, we obtained demographic, laboratory, and medication data from the J-DOPPS phase 4-6 (2009-2017). These clinical data were obtained from 4,260 unique HD patients and from 72 unique Japanese dialysis facilities
(58-59 per phase). The J-DOPPS employs a common protocol using standardized questionnaires to obtain detailed longitudinal patientlevel information, as well as dialysis facility practices and care processes. In the J-DOPPS, a medical questionnaire is administered at study entry to confirm information regarding patient demographics, disease history, and comorbidities previously obtained from patient records. Upon enrollment into the J-DOPPS, and at subsequent 4-month intervals, information on the monthly laboratory values; dialysis-specific information for each treatment session; and an updated medication prescription list, including the dose, strength, and frequency, are obtained from the patients. Details regarding the DOPPS methods have been reported previously [18, 19].

In this study, we analyzed patients diagnosed with diabetes mellitus (DM) who had undergone HD thrice a week for at least 4 months $(N=1,842)$. We excluded patients who lacked an ESA prescription at study entry, as well as any patients with polycystic kidney disease as the primary cause of ESRD; a history of malignancy, gastrointestinal bleeding, liver disease, HIV, or prior kidney transplant or missing data on medication, ESA dose, dry weight, or hemoglobin (Hgb) level $(N=508)$ (shown in Fig. 1).

\section{Primary Exposure}

The primary exposure of interest was having a DPP-4 inhibitor prescription within a 4 -month study period, which was coded as a binary variable. We searched the medications database for terms to identify DPP-4 inhibitor prescriptions, including related spellings, commercial names, and combinations, as appropriate. These included alogliptin, anagliptin, linagliptin, omarigliptin, saxagliptin, sitagliptin, teneligliptin, trelagliptin, and vildagliptin.

\section{Primary Outcomes}

The primary outcomes for analysis were eHypo, which was treated as a binary indicator of eHypo exhibition (eHypo), and the ESA responsiveness index (ERI), which was treated as a continuous variable. Patients with eHypo were defined as those with a mean $\mathrm{Hgb}<10$ and a mean standardized ESA dose $>6,000 \mathrm{U} /$ week over 4 months [5]. We defined ERI [4, 20,21] as mean ESA dose (U/week)/(dry weight $[\mathrm{kg}] \times$ mean $\mathrm{Hgb}[\mathrm{g} / \mathrm{dL}])$, where dry weight was calculated as the post-HD body weight averaged across 3 consecutive HD sessions. At each given Hgb level and dry weight, higher ERI values are indicative of a greater ESA dose requirement. Since single-month ESA and Hgb values may not reflect the "usual" or targeted values, we used the average ESA doses and Hgb values over 4 months for ERI estimation. Since the ERI distribution was skewed, we used the natural log-transformed ERI value.

We obtained monthly information on ESA prescription from the J-DOPPS and expressed it as weekly doses. In Japan, "short-acting" epoetin alfa (and certain biosimilars) and "long-acting" darbepoetin alfa and pegylated epoetin beta are used to treat anemia. To standardize the ESA dose across different preparations, we converted Epoetin Beta Pegol (Mircera) to darbepoetin doses using a 1:2:1 ratio [22] and converted darbepoetin to epoetin doses using a 250:1 ratio [23].

\section{Primary Analysis Models}

We used a "new-user" design, which allows within-patient comparisons to assess the treatment effect on outcomes while reducing the confounding effects of any previous treatments. We compared the periods just before ("pre 4 months") and after ("post 4 months") the first DPP-4 inhibitor prescription (top panel of Fig. 2). Since we could not determine the exact timing of the DPP- 
Fig. 1. Flow diagram showing selection and exclusion criteria for diabetic J-DOPPS patients eligible for current study. J-DOPPS, Japan Dialysis Outcomes and Practice Patterns Study.

Fig. 2. Timing of data collection for study exposure (new DPP-4 prescription) and outcome (change in eHypo from pre- to post-DPP-4 prescription) as well as timing of data collection and matching time period for the unexposed group. ESA, erythropoiesis-stimulating agent; eHypo, ESA hyporesponsiveness.
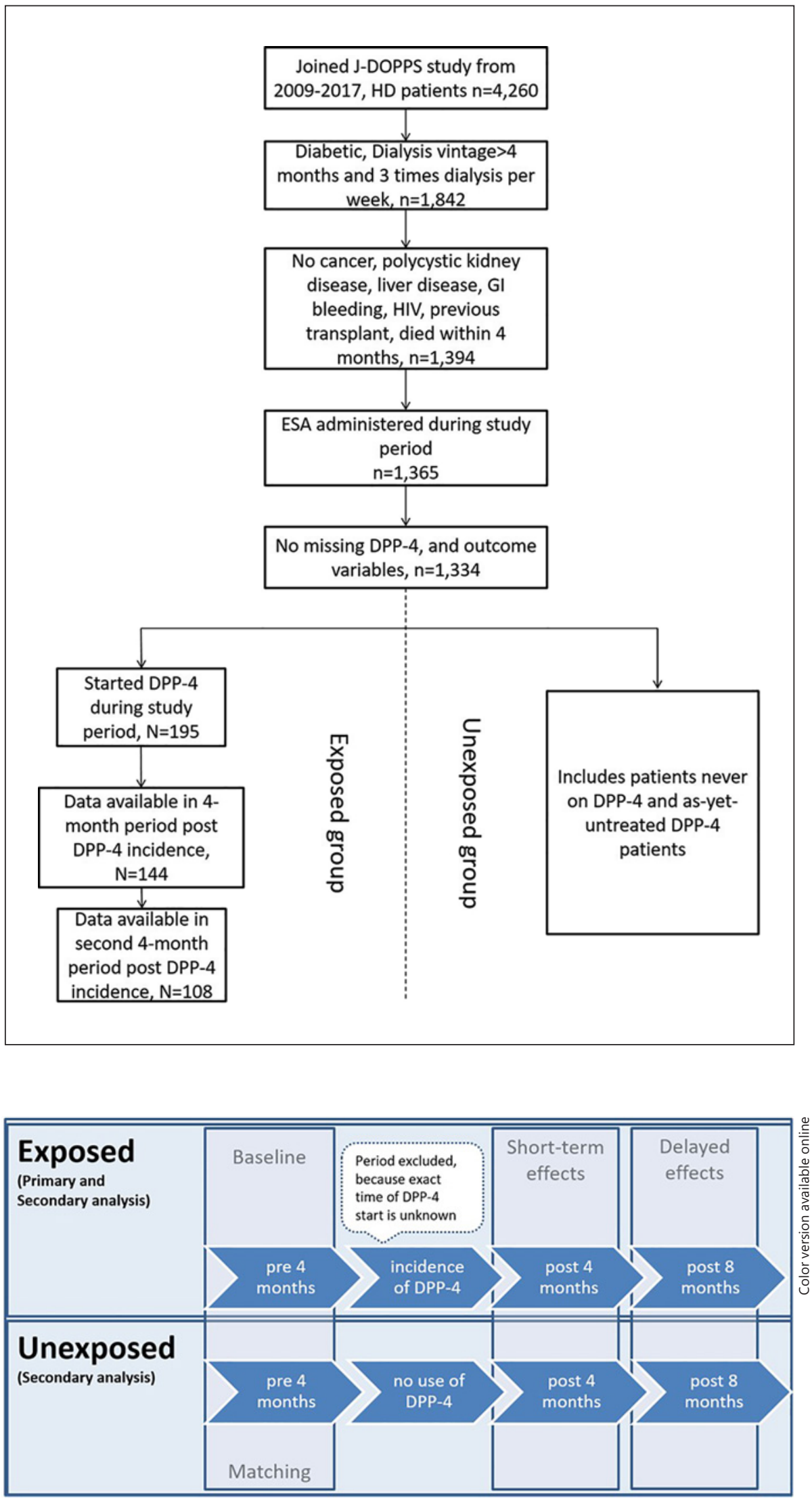

Hasegawa/Zhao/Bieber/Zee/Pisoni/ Robinson/Hanafusa/Nangaku 
4 inhibitor prescription, we excluded the first 4-month period from the analysis ("DPP-4 inhibitor prescription incidence"). Moreover, to account for the potentially delayed effect of DPP-4, we compared the period just before ("pre 4 months") and 2 periods after the DPP-4 inhibitor prescription incidence ("post 8 months").

The primary analysis was conducted on patients who were exposed to DPP-4 during the study period. We used conditional logistic regression to compare binary eHypo outcomes within patients before and after the first DPP-4 inhibitor prescription. Moreover, we used a generalized estimating equation linear model for continuous ERI outcomes by accounting for repeated measurements within the same patient using an exchangeable correlation structure.

Since we compared outcomes within 1 patient at different time points, the patient characteristics, including gender and comorbidities, were similar across time points. Therefore, we did not include these variables as adjustment covariates. Moreover, we did not adjust for age and time on HD since the difference in the variables across time points were identical for all patients. Therefore, we only considered variables that may change over time within a patient and vary across patients as covariates. However, since most of these variables could have been mediators, we reported the results for the unadjusted model and a model adjusted for hospitalizations. Results were also stratified by iron deficiency status (transferrin saturation [TSAT] $<20 \%$ or ferritin $<100 \mathrm{ng} / \mathrm{mL}$ ) prior to DPP-4 prescription.

\section{Secondary Analyses}

To confirm that secular changes did not contribute to the observed treatment effects, we compared these effects between the DPP-4 exposed and unexposed groups. Since we could determine the time and patient characteristics after DPP-4 inhibitor prescription, we selected comparable unexposed patients in the same facility during the same data collection period. The prognostic scores of the 2 patient groups were well matched within certain calipers for relative scores ( 0.5 for binary eHypo outcome and 0.1 for log ERI). Unexposed patients included patients without a DPP-4 inhibitor prescription during the study period (i.e., "never DPP-4") and those who were yet to receive a DPP-4 inhibitor prescription during the matching period (i.e., "as-of-yet untreated"). We developed prognostic score models using data obtained from the unexposed group during the matching period and applied them to both groups to obtain estimated prognostic scores. The prognostic score models were separately fitted for the binary and continuous outcomes and included the following predictors: phase, age, gender, time on HD, comorbidities (coronary artery disease, congestive heart failure, hypertension, other cardiovascular diseases, cerebrovascular disease, lung disease, neurological disease, psychiatric disorder, peripheral vascular disease, and recurring cellulitis/ gangrene), hospitalization, treatment time per session, HD adequacy index, C-reactive protein, albumin, TSAT, and ferritin. To multiply measured predictors during the matching period, we used the first nonmissing value during the period. After matching, we analyzed the matched sets using conditional logistic regression for the binary eHypo outcomes and a mixed model with random effects for the continuous ERI outcomes. The models were further adjusted for the between-group prognostic score ratio to account for imperfect matches. We included an interaction term between the pre- /post-status and exposed/unexposed status in the model as the primary test of interest. Specifically, we considered the "pre

DPP-4 Inhibitor and Erythropoiesis-

Stimulating Agent Hyporesponsiveness
4 months" period as the matching period and the "post 4 months" or "post 8 months" periods as the corresponding intervals after the matching period (Fig. 2).

\section{Treatment of Missing Data}

After forming the analysis dataset, missing covariate values were multiply imputed 20 times using the Sequential Regression Multiple Imputation Method by IVEware [24]. DPP-4, ERI, and eHypo were not imputed; however, they were included in the imputation model as predictors. The proportion of missing data was $<10 \%$ for all the imputed covariates except for TSAT (57\% missing), C-reactive protein (25\% missing), and ferritin (19\% missing). We separately calculated the prognostic scores for each imputed dataset and subsequently used them for matching. The results from the 20 imputed data sets were combined using Rubin's formula for the final analysis [25]. All analyses were conducted using SAS software version 9.4 (SAS Institute Inc., Cary, NC, USA).

\section{Ethical Considerations}

The Ethics Committee of Tokyo Women's Medical University approved the J-DOPPS (approval number: \#678). As required, the institutional review board (IRB) at each facility also approved the study. We obtained written informed consent from each patient consistent with the IRB requirements in each facility. The patients' data were collected with patient anonymity ensured.

\section{Results}

\section{DPP-4 Inhibitor Prescription Incidence and Patient Characteristics}

Among 4,260 patients, 1,334 were eligible for the current study, with 195 (14.6\%) receiving DPP-4 inhibitor prescriptions during the study period. Among these patients, 144 patients had available follow-up data for 4 months after the DPP-4 inhibitor prescription incidence with 108 patients having available follow-up data for the subsequent 8 months (Fig. 1). There was a monotonic increase in the DPP-4 inhibitor prescriptions by study year from $0 \%$ in $2009-20 \%$ in 2017 (2009: 0\%, 2010: 0.2\%, 2011: 2\%, 2012: 5\%, 2013: 9\%, 2014: 14\%, 2015:15\%, 2016: 19\%, and 2017: 20\%) (Fig. 3).

Table 1 presents the patients' characteristics. Most of the demographic and clinical characteristics were similar between the exposed and unexposed patients. However, exposed patients had higher ferritin levels.

Among the 144 patients with follow-up data available for 4 months after the DPP-4 inhibitor prescription incidence, HbA1c on average decreased by $0.15 \%$ and serum glucose decreased by $13 \mathrm{mg} / \mathrm{dL}$. In terms of the outcome of interest, 17 of 144 (11.8\%) were ESA hyporesponsive before the DPP-4 inhibitor prescription compared to 127 patients $(88.2 \%)$ who were ESA responsive (see online suppl. Fig. 1; for all online suppl. material, see www. 
Fig. 3. Percentage of diabetic J-DOPPS patients prescribed DPP-4 by year and 4-month period from 2009 to 2017. *T1, January-April; T2, May-August; T3, September-December. J-DOPPS, Japan Dialysis Outcomes and Practice Patterns Study.

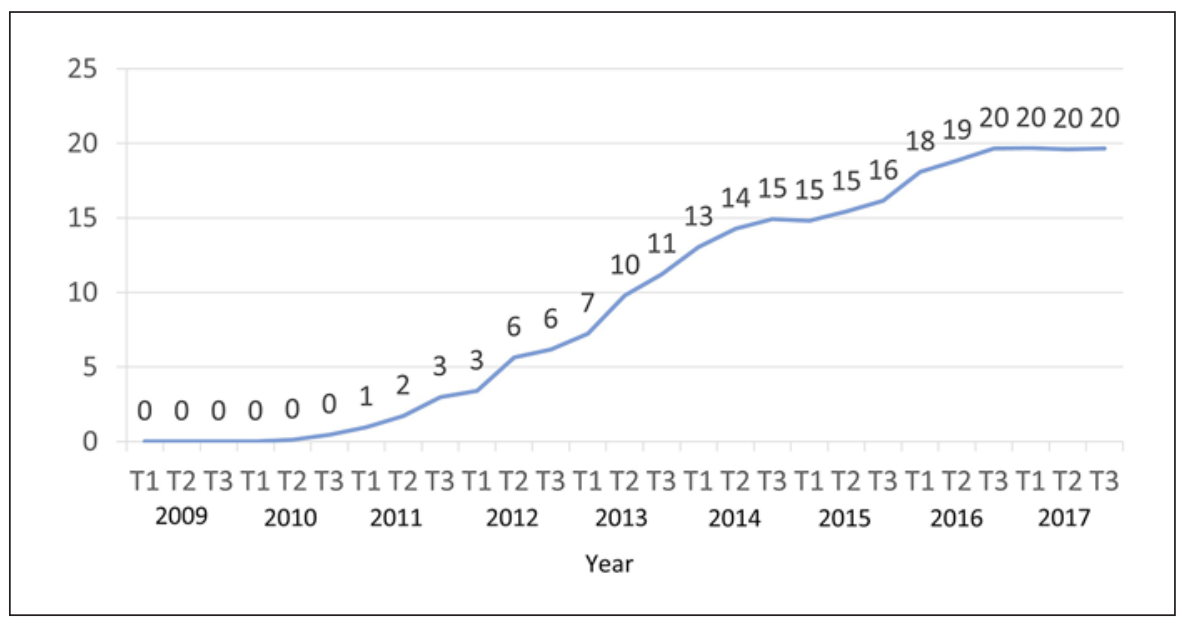

karger.com/doi/10.1159/000515704). In the 4 months after DPP-4 inhibitor prescription 6 of 17 patients who were ESA hyporesponsive before prescription remained ESA hyporesponsive while 11 of the 127 patients who were ESA responsive before DPP-4 inhibitor prescription developed eHypo.

\section{Primary Analysis}

Table 2 presents the results of primary analyses of both outcomes where we compared eHypo and ERI between the 4- and 8-month post-DPP-4 inhibitor periods with the 4-month pre-DPP-4 inhibitor period. The odds of eHypo in the post- and pre-DPP-4 inhibitor period were similar. The odds ratio comparing the 8-month post-DPP-4 inhibitor period and the 4-month preDPP-4 inhibitor period was 1.17 (95\% CI; 0.76-1.18); however, the small number of events for the binary eHypo outcome resulted in wide confidence intervals. Regarding the continuous ERI outcome, the ratio of means was consistent across the models at 1.00 between the preand post-DPP-4 inhibitor periods. Sensitivity analysis after adjustment for hospitalization yielded similar results (Table 2).

To test whether the association with DPP-4 prescription and eHypo differed by iron deficiency, the primary results were stratified by pre-prescription iron deficiency (TSAT $<20 \%$ or ferritin $<100 \mathrm{ng} / \mathrm{mL}$ ). Although sample sizes were small, patients without iron deficiency (compare to patients with iron deficiency) were less likely to be ESA hyporesponsive (interaction $p$ value $=0.05$ ) and had a lower ERI (interaction $p$ value $=0.03$ ) after prescription of DPP-4 (Table 3).

\section{Secondary Analyses}

Table 4 presents the between-period and betweengroup comparison of the observed associations and eHypo, respectively. The test of interest was whether the interaction term was zero, which implies no between-group differences. All $p$ values for these tests were large, which was indicative of no significant between-group differences. The odds ratio for the binary eHypo outcome between the post- and pre-DPP-4 inhibitor periods was 0.95 (95\% CI; $0.48-1.88)$ and 1.74 (95\% CI; $1.10-2.74)$ in the exposed and unexposed groups, respectively, with both having wide confidence intervals. Regarding the continuous outcome, all the mean ratios were close to 1 , which indicated small between-group and between-period differences.

\section{Discussion}

In this study, we described the patterns of DPP-4 inhibitor prescriptions and evaluated the association between DPP-4 inhibitor prescriptions and ESA responsiveness using a representative sample of Japanese HD patients included in J-DOPPS phases 4-6 (2009-2017). We observed a monotonic annual increase in DPP-4 inhibitor prescriptions from $0 \%$ in 2009 to $20 \%$ in 2017. During the study period, $14.6 \%$ of the patients started DPP-4 inhibitors with $12.8 \%$ of them presenting eHypo at baseline. DPP-4 inhibitor prescriptions did not alter the odds of eHypo and mean log-ERI. However, stratification by pre-prescription sideropenia provided evidence that DPP-4 inhibitors may attenuate eHypo in patients without iron deficiency. 
Table 1. Characteristics of diabetic J-DOPPS patients, by prescription of DPP-4 during study follow-up and matching variable

\begin{tabular}{|c|c|c|c|}
\hline \multirow[t]{2}{*}{ Variable } & \multirow[t]{2}{*}{ Prescribed DPP-4 } & \multicolumn{2}{|c|}{ Not prescribed DPP- $4^{\mathrm{a}}$} \\
\hline & & matched by eHypo & matched by log ERI \\
\hline Patients, $N^{\mathrm{b}}$ & 144 & 384 & 447 \\
\hline \multicolumn{4}{|l|}{ Demographicsc } \\
\hline Age, years & $67.0 \pm 10.6$ & $65.7 \pm 10.6$ & $67.0 \pm 9.4$ \\
\hline Male, \% & 59 & 71 & 69 \\
\hline BMI, kg/m² & $23.0 \pm 4.5$ & $22.9 \pm 3.8$ & $22.3 \pm 3.5$ \\
\hline Time on dialysis, years & $4.55 \pm 3.98$ & $4.48 \pm 3.71$ & $4.68 \pm 3.99$ \\
\hline Post-dialysis body weight, $\mathrm{kg}$ & $58.6 \pm 13.1$ & $59.9 \pm 13.2$ & $57.8 \pm 11.7$ \\
\hline \multicolumn{4}{|l|}{ Comorbidities, ${ }^{\mathrm{d}} \%$} \\
\hline Coronary artery disease & 34 & 26 & 28 \\
\hline Other cardiovascular disease & 24 & 19 & 22 \\
\hline Congestive heart failure & 22 & 21 & 26 \\
\hline Cerebrovascular disease & 15 & 13 & 11 \\
\hline Hypertension & 85 & 91 & 89 \\
\hline Lung disease & 1 & 4 & 4 \\
\hline Neurological disease & 5 & 4 & 4 \\
\hline Psychiatric disorder & 5 & 3 & 4 \\
\hline Peripheral vascular disease & 18 & 18 & 16 \\
\hline Recurring cellulitis/gangrene & 5 & 4 & 4 \\
\hline Hospitalization in 4-month period & 18 & 11 & 15 \\
\hline \multicolumn{4}{|l|}{ Dialysis prescription $^{c}$} \\
\hline HD treatment time, min & $239 \pm 28$ & $240 \pm 26$ & $238 \pm 26$ \\
\hline Single pool, Kt/V & $1.41 \pm 0.30$ & $1.38 \pm 0.27$ & $1.40 \pm 0.27$ \\
\hline \multicolumn{4}{|l|}{ Laboratory values ${ }^{c}$} \\
\hline $\mathrm{CRP}, \mathrm{mg} / \mathrm{L}$ & $1.05(0.50,4.00)$ & $1.00(0.60,2.20)$ & $1.00(0.60,3.00)$ \\
\hline Albumin, $\mathrm{g} / \mathrm{dL}$ & $3.63 \pm 0.38$ & $3.73 \pm 0.33$ & $3.70 \pm 0.35$ \\
\hline Ferritin, ng/mL & $92.4(45.3,185.0)$ & $56.5(26.3,121.0)$ & $59.0(27.9,131.4)$ \\
\hline TSAT, $\%$ & $23.2(16.4,29.1)$ & $21.9(15.4,31.8)$ & $21.5(14.6,29.0)$ \\
\hline Total cholesterol, mg/dL & $156 \pm 35$ & $150 \pm 33$ & $151 \pm 35$ \\
\hline LDL cholesterol, mg/dL & $82.6 \pm 25.2$ & $80.6 \pm 27.4$ & $81.3 \pm 28.2$ \\
\hline HDL cholesterol, mg/dL & $46.0 \pm 14.5$ & $47.3 \pm 14.3$ & $46.8 \pm 14.8$ \\
\hline Triglycerides, mg/dL & $136 \pm 77$ & $124 \pm 63$ & $125 \pm 67$ \\
\hline $\mathrm{Hgb} \mathrm{A} 1 \mathrm{c}, \%^{\mathrm{e}}$ & $6.49 \pm 0.98$ & $6.13 \pm 0.95$ & $6.09 \pm 0.96$ \\
\hline $\mathrm{Hgb}, \mathrm{g} / \mathrm{dL}$ & $10.7 \pm 0.9$ & $10.7 \pm 0.9$ & $10.6 \pm 0.9$ \\
\hline ESA dose, unit/week & $5,435(3,699,8,900)$ & $5,435(3,261,7,473)$ & $5,435(3,397,8,153)$ \\
\hline
\end{tabular}

Results are shown as mean \pm standard deviation, median (25th and 75th percentile), or prevalence. J-DOPPS, Japan Dialysis Outcomes and Practice Patterns Study; DPP-4, Dipeptidyl Peptidase-4 Inhibitor; eHypo, ESA hyporesponsive (mean $\mathrm{Hgb}<10$ and a mean standardized ESA dose $>6,000$ U/week over 4/8 months); ERI, ESA responsiveness index (mean ESA dose [U/week]/[dry weight $\{\mathrm{kg}\} \times$ mean $\mathrm{Hgb}\{\mathrm{g} / \mathrm{dL}\}]$ ); CRP, C-reactive protein; TSAT, transferrin saturation; LDL, low density lipoprotein; HDL, high density lipoprotein; HD, hemodialysis;

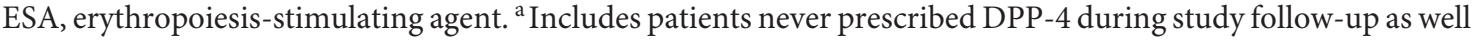
as patients yet to be prescribed DPP-4 during the matching period; patients not prescribed DPP- 4 were matched $\mathrm{n}: 1$ with patients prescribed DPP-4. ${ }^{\mathrm{b}}$ Different numbers of patients were matched for each of 20 imputation. For illustration purposes, only data from imputation 1 are shown. ${ }^{c}$ Most recent value at time of DPP-4 prescription (or matching for patients not prescribed DPP-4). ${ }^{\mathrm{d}}$ Assessed at study enrollment with exception of hospitalization. ${ }^{\mathrm{e}}$ Missingness is $49 \%$ in patients prescribed DPP-4, 50 and 52\% in eHypo and log ERI-matched group respectively.

We observed a steep increase in the DPP-4 inhibitor prescriptions in the J-DOPPS cohort with $20 \%$ of the patients having a DPP-4 inhibitor prescription by the end of 2017. This is consistent with a population-based study in Ontario, Canada that reported a similar increasing trend in DPP-4 inhibitor prescriptions from 2004 (0\%) to 2013 (17.3\%) [26]. Meanwhile, a French study using the National Health Insurance database showed that $38 \%$ of 
Table 2. Change in eHypo among diabetic J-DOPPS patients before and after new DPP-4 prescription by number of months over which the outcome was assessed, with and without adjustment for hospitalization during the pre-DPP-4 assessment period

\begin{tabular}{|c|c|c|c|c|c|c|c|c|c|}
\hline \multirow[t]{3}{*}{$\begin{array}{l}\text { Months after } \\
\text { first DPP- } 4 \mathrm{Rx}\end{array}$} & \multirow[t]{3}{*}{$\begin{array}{l}\text { Exposure } \\
\text { period }\end{array}$} & \multirow[t]{3}{*}{$\begin{array}{l}\text { Mean Hgb, } \\
\text { g/dL }\end{array}$} & \multirow{3}{*}{$\begin{array}{l}\text { Mean ESA } \\
\text { dose, } \\
\text { U/week }\end{array}$} & \multirow[t]{3}{*}{ \% еНуро } & \multirow{3}{*}{$\begin{array}{l}\text { Mean ERI, unit/ } \\
\text { week } / \mathrm{kg} / \mathrm{g} \text { per } \\
\mathrm{dL}\end{array}$} & \multicolumn{2}{|l|}{$\begin{array}{l}\text { Outcome } \\
\text { Unadjusted }\end{array}$} & \multicolumn{2}{|c|}{$\begin{array}{l}\text { Outcome } \\
\text { Adjusted for hospitalization }{ }^{\mathrm{a}}\end{array}$} \\
\hline & & & & & & $\begin{array}{l}\text { eHypo odds ratio } \\
(95 \% \mathrm{CI})\end{array}$ & $\begin{array}{l}\text { ERI ratio of } \\
\text { means }(95 \% \mathrm{CI})\end{array}$ & $\begin{array}{l}\text { eHypo odds ratio } \\
(95 \% \text { CI })\end{array}$ & $\begin{array}{l}\text { ERI ratio of } \\
\text { means }(95 \% \\
\text { CI) }\end{array}$ \\
\hline & & & & & & post versus pre & post versus pre & post versus pre & post versus pre \\
\hline $\begin{array}{l}4 \text { months } \\
(N=144)\end{array}$ & Post & 10.6 & 7,301 & $11.8 \%^{\mathrm{b}}$ & 13.1 & $1.00(0.63,1.59)$ & $1.00(0.89,1.12)$ & $1.04(0.63,1.75)$ & $1.00(0.90,1.12)$ \\
\hline \multirow{2}{*}{$\begin{array}{l}8 \text { months } \\
(N=108)\end{array}$} & Post & 10.7 & 7,321 & $17.6 \%^{\mathrm{c}}$ & 12.8 & \multirow{2}{*}{$1.17(0.76,1.81)$} & \multirow{2}{*}{$1.00(0.88,1.14)$} & \multirow{2}{*}{$1.11(0.70,1.77)$} & \multirow{2}{*}{$0.98(0.86,1.11)$} \\
\hline & Pre & 10.6 & 7,792 & $13.9 \%$ & 13.2 & & & & \\
\hline
\end{tabular}

Separate models for each outcome and time period over which outcome was assessed (4 and 8 months). ESA, erythropoiesis-stimulating agent; J-DOPPS, Japan Dialysis Outcomes and Practice Patterns Study; DPP-4, Dipeptidyl Peptidase-4 Inhibitor; Rx, prescription; Hgb, hemoglobin; eHypo, ESA hyporesponsive (mean $\mathrm{Hgb}<10$ and a mean standardized ESA dose $>6,000 \mathrm{U} /$ week over 4 months); ERI, ESA responsiveness index (mean ESA dose (U/ week)/[dry weight $\{\mathrm{kg}\} \times$ mean $\mathrm{Hgb}\{\mathrm{g} / \mathrm{dL}\}])$; eHypo, ESA hyporesponsiveness. ${ }^{\text {a }}$ Hospitalization at any point during the pre-DPP-4 assessment periods. ${ }^{\mathrm{b}}$ Among the 17 ESA hyporesponsive patients pre-DPP-4 prescription, 6 patients remained ESA hyporesponsive; among the 127 ESA responsive patients pre-DPP-4 prescription, 11 developed eHypo ${ }^{\mathrm{c}}{ }^{\mathrm{A}}$ mong the 15 ESA hyporesponsive patients pre-DPP-4 prescription 4 patients remained ESA hyporesponsive; among the 93 ESA responsive patients pre- DPP-4 prescription, 15 developed eHypo.

Table 3. Change in eHypo among diabetic J-DOPPS patients before and after new DPP-4 prescription, by pre-DPP-4 prescription and pre-prescription iron deficiency

\begin{tabular}{|c|c|c|c|c|c|c|c|}
\hline \multirow[t]{2}{*}{$\begin{array}{l}\text { Pre-DPP- } 4 \text { iron } \\
\text { deficiency }{ }^{b}\end{array}$} & \multirow[t]{2}{*}{$\begin{array}{l}\text { Exposure } \\
\text { period }\end{array}$} & \multirow[t]{2}{*}{$\begin{array}{l}\text { Mean Hgb, } \\
\text { g/dL }\end{array}$} & \multirow{2}{*}{$\begin{array}{l}\text { Mean ESA } \\
\text { dose, U/ } \\
\text { week }\end{array}$} & \multirow[t]{2}{*}{ \% еНуро } & \multirow{2}{*}{$\begin{array}{l}\text { Mean ERI, unit/ } \\
\text { week/kg/g per } \\
\text { dL }\end{array}$} & \multicolumn{2}{|c|}{$\begin{array}{l}\text { Outcome } \\
\text { Adjusted for hospitalization }{ }^{a}\end{array}$} \\
\hline & & & & & & $\begin{array}{l}\text { eHypo odds ratio } \\
(95 \% \mathrm{CI}) \\
\text { post versus pre }\end{array}$ & $\begin{array}{l}\text { ERI ratio of means } \\
(95 \% \mathrm{CI}) \\
\text { post versus pre }\end{array}$ \\
\hline Yes $(N=96)$ & Post & 10.7 & 7,769 & $14 \%^{\mathrm{c}}$ & 14.1 & $1.29(0.57,3.28)$ & $1.03(0.90,1.19)$ \\
\hline \multirow[t]{2}{*}{ No $(N=18)$} & Post & 11.0 & 7,022 & $0 \%^{\mathrm{d}}$ & 11.4 & \multirow{2}{*}{$0.64\left(0.00^{\mathrm{e}}, 1.86\right)$} & \multirow{2}{*}{$0.73(0.56,0.94)$} \\
\hline & Pre & 10.5 & 10,000 & $17 \%$ & 18.2 & & \\
\hline Interaction $p$ value & & & & & & 0.05 & 0.03 \\
\hline
\end{tabular}

Separate models for each outcome and iron deficient versus noniron deficient patients. ESA, erythropoiesis-stimulating agent; J-DOPPS, Japan Dialysis Outcomes and Practice Patterns Study; DPP-4, Dipeptidyl Peptidase-4 Inhibitor; Rx, prescription; Hgb, hemoglobin; eHypo, ESA hyporesponsive (mean $\mathrm{Hgb}<10$ and a mean standardized ESA dose $>6,000$ U/week over 4 months); ERI, ESA responsiveness index (mean ESA dose (U/week)/[dry weight $\{\mathrm{kg}\} \times$ mean $\mathrm{Hgb}\{\mathrm{g} / \mathrm{dL}\}]$ ); eHypo, ESA responsiveness; TSAT, transferrin saturation. ${ }^{a}$ Hospitalization at any point during the pre-DPP- 4 assessment periods. ${ }^{\mathrm{b}} \mathrm{TSAT}<20 \%$ or ferritin $<100 \mathrm{ng} / \mathrm{mL}$; the most recent values before the first DPP-4 prescription were used. ${ }^{c}$ Among the 12 iron deficient ESA hyporesponsive patients pre-DPP-4 prescription, 6 patients remained ESA hyporesponsive; among the 83 iron deficient ESA responsive patients pre-DPP-4 prescription, 6 developed eHypo. ${ }^{\mathrm{d}}$ Among the 3 noniron deficient ESA hyporesponsive patients pre-DPP-4 prescription no patient remained ESA hyporesponsive; among the 15 noniron deficient ESA responsive patients pre-DPP-4 prescription, 0 developed eHypo. ${ }^{\mathrm{e}} 0.00$ lower limit obtained by exact calculation of confidence interval due to empty cell ( 0 of 18 patients were hyporesponsive post-DPP-4. 
Table 4. Change in eHypo among diabetic J-DOPPS patients by DPP-4 prescription and time frame for exposure and outcome assessment

\begin{tabular}{|c|c|c|c|c|c|c|c|c|}
\hline \multirow{2}{*}{$\begin{array}{l}\text { Exposure } \\
\text { assessment }\end{array}$} & \multirow{2}{*}{$\begin{array}{l}\text { Outcome } \\
\text { assessment }\end{array}$} & \multirow[t]{2}{*}{$\mathrm{DPP}-4 \mathrm{Rx}$} & \multicolumn{3}{|c|}{ eHypo outcome } & \multicolumn{3}{|c|}{ ERI outcome } \\
\hline & & & $N \mathrm{pts}^{\mathrm{a}}$ & post versus pre & $\begin{array}{l}\text { DPP-4* } \\
\text { pre-/post- } \\
\text { interaction } \\
p \text { value }\end{array}$ & $N \mathrm{pts}^{\mathrm{a}}$ & post versus pre & $\begin{array}{l}\text { DPP-4* } \\
\text { pre-/post- } \\
\text { interaction } \\
p \text { value }\end{array}$ \\
\hline \multirow[t]{3}{*}{4 months } & 4 months & No & 384 & $1.74(1.10-2.74)$ & 0.15 & 447 & $1.04[0.97,1.11]$ & 0.72 \\
\hline & \multirow[t]{2}{*}{8 months } & No & 275 & $1.50(0.78-2.88)$ & \multirow{2}{*}{0.92} & 311 & $0.99[0.90,1.09]$ & \multirow{2}{*}{0.96} \\
\hline & & Yes & 100 & $1.43(0.70-2.90)$ & & 98 & $1.00[0.85,1.16]$ & \\
\hline
\end{tabular}

ESA, erythropoiesis-stimulating agent; J-DOPPS, Japan Dialysis Outcomes and Practice Patterns Study; DPP-4, Dipeptidyl Peptidase-4 Inhibitor; Rx, prescription; Hgb, hemoglobin; eHypo, ESA hyporesponsive (mean Hgb $<10$ and a mean standardized ESA dose $>6,000$ U/week over 4/8 months); ERI, ESA responsiveness index (mean ESA dose (U/week)/[dry weight $\{\mathrm{kg}\} \times \mathrm{mean} \mathrm{Hgb}\{\mathrm{g} / \mathrm{dL}\}]$ ); eHypo, ESA responsiveness. ${ }^{a}$ Different numbers of patients were matched for each imputation. For illustration purposes, only the numbers of patients from imputation 1 are shown. Patients newly prescribed DPP-4 were matched 1: $N$ to as-of-yet untreated patients based on adjusted prognostic scores for baseline eHypo or $\log (\mathrm{ERI})$.

2,378 incident dialysis patients with diabetes had received oral antidiabetic medication 6 months before the initiation of dialysis, and DPP-4 inhibitors were prescribed to $6 \%$ of patients [27].

Our findings contradict the subsequently discussed previous reports. A recent open-label randomized controlled trial (RCT) examined the efficacy and safety of saxagliptin, a DPP-4 inhibitor, in $82 \mathrm{HD}$ patients [16]. This previous RCT measured the ERI as a secondary endpoint with higher ERI values indicating greater eHypo. Compared with the control group (usual care), there was a significant decrease in ERI in the saxagliptin group. Moreover, a small-scale, before-after observational study reported a significant reduction in ERI after linagliptin (another DPP-4 inhibitor type) use in $25 \mathrm{HD}$ patients with DM [17]. As the 2 previous studies mentioned above did not examine the interaction between DPP-4 inhibitors use and iron deficiency, we consider that the results of the present study could be different from those of them. Sitagliptin, a DPP-4 inhibitor, has been reported to in-

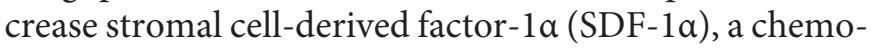
kine derived from stromal cells [28]. SDF-1 $\alpha$ acts as a renal natriuretic and also plays an important role in myelopoiesis. Therefore, the regulation mechanism of SDF-1a by DPP- 4 inhibitors may be one of the theoretical bases for the ameliorating effect of DPP-4 inhibitors on ESAresistant anemia.
Previous RCTs have demonstrated that DPP-4 inhibitors provide effective glycemic control with good tolerability in individuals with or without CKD, including ESRD. Several recent systematic reviews have suggested that DPP-4 inhibitors have beneficial effects on glycemic control in patients with diabetes with comorbid CKD, including ESRD, without increasing the risk of adverse events involving hypoglycemic episodes $[29,30]$. Our findings also showed that DPP-4 inhibitors improved glycemic control in patients undergoing HD. The generalizability of our findings is improved by the fact that the J-DOPPS collects data from a national representative sample of HD patients in Japan. We used detailed clinical information to control for possible confounders that could have a bias effect on the association between DPP-4 inhibitor prescription and ESA responsiveness.

However, this study had several limitations, including its observational nature. Additionally, information on oral medications (e.g., DPP-4 inhibitors) is collected infrequently (4-month intervals) in the J-DOPPS and is restricted to the prescription. Therefore, our findings are affected by the unmeasured actual consumption of DPP4 inhibitors. Decreased use of DPP-4 inhibitors relative to DPP-4 inhibitor prescription could result in a bias toward the null hypothesis value (no effect). Furthermore, regarding the secondary analyses involving the betweengroup comparison of DPP-4 inhibitors, we assumed that 
the choice for prescribing DPP-4 inhibitors was independent of the patient's eHypo or unmeasured variables. If this assumption is incorrect, the resulting treatment-byindication bias could result in overestimation of the differences in the association between eHypo and DPP-4 inhibitors in both groups.

Despite showing promising results in a small-scale RCT and pilot before-after observational study, there was no difference in the odds of eHypo in HD patients with DM before and after DPP-4 inhibitor prescription in the whole cohort of our study. However, based on the results of the interaction analysis of the present study, we have made the following recommendations: (1) DPP-4 inhibitors could be useful in improving ERI in patients undergoing HD without iron deficiency, and (2) we should correct the iron deficiency when DPP-4 inhibitors were being used in those patients. In conclusion, the clinical effectiveness of DPP-4 inhibitors in renal anemia management of HD patients with DM remains unclear.

\section{Acknowledgements}

We would like to express our appreciation to members of the J-DOPPS steering committee; Drs. Kiyoshi Kurokawa, Akira Saito, Tadao Akizawa, Takashi Akiba, Shunichi Fukuhara, Kousaku Nitta, Masaaki Inaba, Masafumi Fukagawa, and Kazuhiko Tsuruya. Moreover, we offer warm thanks to the study nurses, physicians, medical directors, and the study participants of JDOPPS. Preliminary findings of this study were previously published in abstract form at 55th ERA-EDTA Congress 2018 in Copenhagen, Denmark. https://doi.org/10.1093/ndt/gfy104.SP345.

\section{Statement of Ethics}

The Ethics Committee of Tokyo Women's Medical University approved the J-DOPPS (approval number: \#678). As required, the IRB at each facility also approved the study. Consistent with the IRB requirements in each facility, we obtained written informed consent from each sampled patient. The sampled patients' data were collected with patient anonymity ensured.

\section{Conflict of Interest Statement}

T.H. has consultancy agreements with Kyowa Kirin Corporation and has received honoraria from Kyowa Kirin Corporation. N.H. has consultancy agreements with Kyowa Kirin Corporation and has received honoraria from Kyowa Kirin Corporation. M.N. has honorarium and research grants from Kyowa Kirin, MSD, ONO, Takeda, Mitsubishi-Tanabe, and Daiichi-Sankyo.

\section{Funding Sources}

J-DOPPS is supported by research grants from Kyowa Kirin Corporation without restrictions on publications. The DOPPS Program is coordinated by Arbor Research Collaborative for Health, Ann Arbor, MI USA.

\section{Author Contributions}

T.H., J.Z., B.B., J.Z., and R.L.P.: research concept and study design. J.Z., B.B., and J.Z.: data acquisition and analysis. T.H., R.L.P., B.M.R., N.H., and M.M.: interpretation. N.H. and M.M.: supervision. Each author contributed important intellectual content during manuscript drafting and agrees to ensure the accuracy or integrity of any manuscript section.

\section{References}

1 American Diabetes Association. 11. microvascular complications and foot care: standards of medical care in diabetes-2020. Diabetes Care. 2020 Jan;43(Suppl 1):S13-151.

2 Hocher B, Reichetzeder C, Alter ML. Renal and cardiac effects of DPP4 inhibitors: from preclinical development to clinical research. Kidney Blood Press Res. 2012 Aug;36(1):6584.

3 Zhang Y, Thamer M, Stefanik K, Kaufman J, Cotter DJ. Epoetin requirements predict mortality in hemodialysis patients. Am J Kidney Dis. 2004 Nov;44(5):866-76.

4 Panichi V, Rosati A, Bigazzi R, Paoletti S, Mantuano E, Beati S, et al. Anaemia and resistance to erythropoiesis-stimulating agents as prognostic factors in haemodialysis patients: results from the RISCAVID study. Nephrol Dial Transplant. 2011 Aug;26(8):2641-8.
5 Fukuma S, Yamaguchi T, Hashimoto S, Nakai S, Iseki K, Tsubakihara Y, et al. Erythropoiesis-stimulating agent responsiveness and mortality in hemodialysis patients: results from a cohort study from the dialysis registry in Japan. Am J Kidney Dis. 2012 Jan;59(1): 108-16.

6 Koulouridis I, Alfayez M, Trikalinos TA, Balk EM, Jaber BL. Dose of erythropoiesis-stimulating agents and adverse outcomes in CKD: a metaregression analysis. Am J Kidney Dis. 2013 Jan;61(1):44-56.

7 Hasegawa T, Koiwa F, Akizawa T. Anemia in conventional hemodialysis: finding the optimal treatment balance. Semin Dial. 2018 Nov; 31(6):599-606.

8 Broxmeyer HE, Hoggatt J, O'Leary HA, Mantel C, Chitteti BR, Cooper S, et al. Dipeptidylpeptidase 4 negatively regulates colony-stimulating factor activity and stress hematopoiesis. Nat Med. 2012 Dec;18(12):1786-96.
9 Ou X, O'Leary HA, Broxmeyer HE. Implications of DPP4 modification of proteins that regulate stem/progenitor and more mature cell types. Blood. 2013 Jul;122(2):161-9.

10 Alter ML, Ott IM, von Websky K, Tsuprykov O, Sharkovska Y, Krause-Relle K, et al. DPP-4 inhibition on top of angiotensin receptor blockade offers a new therapeutic approach for diabetic nephropathy. Kidney Blood Press Res. 2012 Oct;36(1):119-30.

11 Satoh-Asahara N, Sasaki Y, Wada H, Tochiya M, Iguchi A, Nakagawachi R, et al. A dipeptidyl peptidase- 4 inhibitor, sitagliptin, exerts anti-inflammatory effects in type 2 diabetic patients. Metab Clin Exp. 2013 Mar;62(3): 347-51.

12 Avogaro A, Fadini GP. The effects of dipeptidyl peptidase- 4 inhibition on microvascular diabetes complications. Diabetes care. 2014 Oct;37(10):2884-94. 
13 Nakamura Y, Tsuji M, Hasegawa H, Kimura $\mathrm{K}$, Fujita $\mathrm{K}$, Inoue $\mathrm{M}$, et al. Anti-inflammatory effects of linagliptin in hemodialysis patients with diabetes. Hemodial Int. 2014 Apr; 18(2):433-42.

14 Kothari V, Galdo JA, Mathews ST. Hypoglycemic agents and potential anti-inflammatory activity. J Inflamm Res. 2016 Apr;9:27-38.

15 Iwakura T, Zhao Z, Marschner JA, Devarapu SK, Yasuda H, Anders HJ. Dipeptidyl peptidase-4 inhibitor teneligliptin accelerates recovery from cisplatin-induced acute kidney injury by attenuating inflammation and promoting tubular regeneration. Nephrol Dia Transplant. 2019 Oct;34(10):1669-80.

16 Abe M, Higuchi T, Moriuchi M, Okamura M, Tei R, Nagura C, et al. Efficacy and safety of saxagliptin, a dipeptidyl peptidase- 4 inhibitor, in hemodialysis patients with diabetic nephropathy: a randomized open-label prospective trial. Diabetes Res Clin Pract. 2016 Jun;116:244-52.

17 Aono M, Sato Y. Dipeptidyl peptidase 4 inhibitor linagliptin can decrease the dosage of erythropoiesis-stimulating agents in patients on hemodialysis. Ren Replace Ther. 2016; 2(1):44.

18 Young EW, Goodkin DA, Mapes DL, Port FK, Keen ML, Chen K, et al. The dialysis outcomes and practice patterns study (DOPPS) an international hemodialysis study. Kidney Int. 2000 Jan;57(Suppl 74):S74-81.
19 Pisoni RL, Gillespie BW, Dickinson DM, Chen K, Kutner MH, Wolfe RA. The dialysis outcomes and practice patterns study (DOPPS): design, data elements, and methodology. Am J Kidney Dis. 2004 Nov;44(5 Suppl 2):7-15.

20 Reuter SE, Faull RJ, Ranieri E, Evans AM. Endogenous plasma carnitine pool composition and response to erythropoietin treatment in chronic haemodialysis patients. Nephrol Dial Transplant. 2009 Mar;24(3):990-6.

21 Hasegawa T, Zhao J, Fuller DS, Bieber B, Zee J, Morgenstern $\mathrm{H}$, et al. Erythropoietin hyporesponsiveness in dialysis patients: possible role of statins. Am J Nephrol. 2017 Jun;46(1): $11-7$.

22 Choi P, Farouk M, Manamley N, Addison J. Dose conversion ratio in hemodialysis patients switched from darbepoetin alfa to PEGepoetin beta: AFFIRM study. Adv Ther. 2013 Nov;30(11):1007-17.

23 Bock HA, Hirt-Minkowski P, Brünisholz M, Keusch G, Rey S, von Albertini B. Darbepoetin alpha in lower-than-equimolar doses maintains haemoglobin levels in stable haemodialysis patients converting from epoetin alpha/beta. Nephrol Dial Transplant. 2008 Jan;23(1):301-8.
24 Raghunathan TE, Solenberger PW, Hoewyk JV. IVEware: imputation and variance estimation software. 2007.

25 Little RD. Statistical analysis with missing data. New York: Wiley; 1987.

26 Clemens KK, Liu K, Shariff S, Schernthaner G, Tangri N, Garg AX. Secular trends in antihyperglycaemic medication prescriptions in older adults with diabetes and chronic kidney disease: 2004-2013. Diabetes Obes Metab. 2016 Jun;18(6):607-14.

27 Tuppin P, Cuerq A, Torre S, Couchoud C, Fagot-Campagna A. Management of diabetes patients during the year prior to initiation of dialysis in France. Diabetes Metab. 2017 Jun; 43(3):265-8.

28 Lovshin JA, Rajasekeran H, Lytvyn Y, Lovblom LE, Khan S, Alemu R, et al. Dipeptidyl Peptidase 4 Inhibition stimulates distal tubular natriuresis and increases in circulating SDF-1a(1-67) in patients with type 2 diabetes. Diabetes care. 2017 Aug;40(8):1073-81.

29 Kamiya $\mathrm{H}$. A systematic review of the benefits and harms of dipeptidyl peptidase- 4 inhibitor for chronic kidney disease. Hemodial Int. 2017 Jan;21(1):72-83.

30 Walker SR, Komenda P, Khojah S, Al-Tuwaijri W, MacDonald K, Hiebert B, et al. Dipeptidyl peptidase-4 inhibitors in chronic kidney disease: a systematic review of randomized clinical trials. Nephron. 2017;136(2): 85-94. 